\title{
Validation of diabetes mellitus patient behavior questionnaire in primary health care service
}

\author{
Ginanjar Zukhruf Saputri' ${ }^{1}$, Akrom $^{2}$, Haafizah Dania ${ }^{3}$, Okta Muthia $\mathbf{S}^{4}$ \\ ${ }_{1,2,3}$ Faculty of Pharmacy, Universitas Ahmad Dahlan, Indonesia \\ ${ }^{4}$ Faculty of Mathematics and Natural Sciences, Lambung Mangkurat University, Indonesia
}

\begin{abstract}
Article Info
Article history:

Received Feb 20, 2019

Revised Nov 20, 2019

Accepted Nov 29, 2019

\section{Keywords:}

Adherence

Behaviour,

Diabetes mellitus

Reliability

Validation

ABSTRACT

This study aimed to develop and validation a questionnaire as measurement instrument for knowledge and adherence behavior of DM patients in primary health care. Cross sectional study design was conducted in diabetes mellitus patient. Inclusion criteria were patients in the age group 18-65 years, diagnosed with DM, receiving at least one oral antidiabetic medication. Questionnaire questions for behavioral item were developed based on Diabetes Mellitus management guidelines and references to previous studies. Evaluation and validation by expert was carried out on diabetes mellitus experts and clinical psychologists. The pilot study was conducted on 10 healthy patients and 10 patients with diabetes who enrolled inclusion criteria. Questionnaire validation test was conducted with 41 DM outpatient at PKU Muhammadiyah Hospital in Yogyakarta. Collecting data by interviewing patients based on questionnaire. Statistical analysis was performed using SPSS with Pearson correlation coefficients for validation test and Cronbach alpha coefficients for reliability test of the questionnaire. Adherence behavior questionnaire consists of 12 question items, which are divided into three domains: cognitive, affective, and psychomotor domains. Validation results showed 12 valid items where the pearson correlation value was $>0.308$ $(n=41)$. Cronbach alpha as reliability test results showed 0.78 . This result showed a questionnaire were valid and reliable in Diabetes Mellitus patients. This instrument would be use in primary health care for measuring adherence behavior of DM patients.
\end{abstract}

Copyright (C) 2019 Institute of Advanced Engineering and Science. All rights reserved.

\section{Corresponding Author:}

Ginanjar Zukhruf Saputri,

Faculty of Pharmacy Universitas Ahmad Dahlan,

Jl. Prof. Dr. Soepomo S,H, Warungboto, Yogyakarta 55164, Indonesia.

Email: zukhruf.alparslan@gmail.com

\section{INTRODUCTION}

Diabetes mellitus (DM) belongs to a group of chronic metabolic disorders characterized by hyperglycemia, with abnormalities in the metabolism of carbohydrates, fats, and proteins as a result of insulin insufficiency [1]. Globally, the number of DM patients persistently increases every year. In 2010, it reached 285 million, and $6.6 \%$ of them were in the age range of 20-79 years [2]. The Indonesia Health Profile places DM at the sixth of ten major diseases suffered by hospital outpatients in the country in 2012 [3].

Several clinical trials have proven that pharmacological therapy can reduce the mortality rate of cardiovascular complications from hypertension [4], but non-compliance and non-concordance among patients undergoing this treatment remain high [5]. Here, non-compliance is attributable to many factors, including medication cost, drug regimen, patient, family, and low cognitive in geriatric patients [5-6]. Knowledge and right attitude or behavior toward diseases and their corresponding treatment are unfortunately less than adequate to improve the health status because most well-informed patients with, 
for instance, type 2 diabetes mellitus do not translate their knowledge into positive characters nor healthy habits in their diet, physical exercise, and weight management [7-8].

As developed by the Diabetes Self-Management, the essential components of DM management are education and lifestyle intervention, as well as control of blood glucose level, hypertension, and hyperlipidemia to achieve the goals of the therapy [9]. Education about lifestyle modification, diet, physical exercise, and danger of smoking habits is fundamental in DM management [10-11]. Conducting a study in Ethiopia, Mustefa et al., conclude that lifestyle modification is essential in type 2 DM prevention and management [11]. It incorporates the dissemination of knowledge of healthy lifestyles, such as exercise, weight management, eating pattern, and low-carbohydrate diets. Health workers are shown to play a role in promoting or encouraging changes in healthy behavior among patients with type $2 \mathrm{DM}$.

Previous studies have developed behavioral questionnaires for DM patients with two comorbidities, which are hypertension and hyperlipidemia, for hospitals in the Special Region of Yogyakarta, Indonesia [12-13]. In contrast, this study integrates the government policies on health insurance named BPJS, which prioritizes most type $2 \mathrm{DM}$ patients without complications to receives outpatient treatment in community health centers (primary care services). For this reason, an instrument to screen and assess the behavior of type $2 \mathrm{DM}$ patients as an attempt to identify and facilitate counseling by pharmacists in primary care services has been designed.

The level of behavior is gauged from several aspects, including knowledge of type 2 DM management, lifestyle modification, exercise, and compliance with oral antidiabetic therapy. A questionnaire as an instrument to measure each aspect and its contribution to said behavior, thereby, needs to be formulated. For this reason, the study was designed to create and validate the questionnaire on the behavior of DM patients in primary healthcare services.

\section{RESEARCH METHOD}

This research has been reviewed and approved by the Research Ethics Committee of Ahmad Dahlan University (KEPK UAD). The questionnaire on the behavior of DM patients was compiled based on the DM management guidelines and by referring to previous relevant studies concerning the development of questionnaires on DM knowledge and behavior through Focus Group Discussion (FGD). Evaluation and validation by experts involved doctors competent in Diabetes Mellitus, clinical psychologists, and pharmacists. A pilot test was conducted to evaluate whether or not the questionnaire was feasible to understand the behavior of DM patients. The questionnaire was tested on ten (10) healthy respondents and ten (10) type $2 \mathrm{DM}$ patients who met the inclusion criteria.

Afterward, it was subjected to validity and reliability analyses that involved forty-one (41) type 2 DM patients undergoing outpatient treatment at the PKU Muhammadiyah Hospital in the City of Yogyakarta. In this validity test, the respondents were interviewed with the compiled questionnaire. The inclusion criteria were male and female patients aged 18-65 years old who were cooperative with the research procedure, were diagnosed with type 2 diabetes, and took oral antidiabetic medication. Meanwhile, the exclusion criteria were illiteracy, hearing impairment, and pregnancy. During the data collection, standardized or licensed pharmacists were asked to interview the selected respondents with the questionnaire.

The questionnaire on the behavior of DM patients was written in Indonesian, and it comprised 12 items of yes/no questions belonging to three domains, namely cognitive, affective, and psychomotor. Score 1 was assigned to each 'yes' answer, while score 0 to each 'no' answer. This scoring applied to all items except for questions No. 7 and 12 in which 'yes' answer was given score 1, while each 'no' answer was 0 . The behavior of DM patients was categorized into four levels, namely pre-contemplation (no correct answers in all three domains), contemplation (only the cognitive domain was correctly answered), preparation (both cognitive and affective domains were correctly answered), and action (correct answers in all three domains).

\section{RESULT AND DISCUSSION}

This study involved forty-one (41) type 2 DM patients, most of which were female $(58.5 \%)$ with a status of married (100\%). This result similar to previous study that majority diabetic patients are women [11, 14-16]. More than half of them were older than 61 years old $(58.5 \%)$ and had attended formal education of more than nine years (high school or higher education; 78.0\%). The majority of them had no history of DM (63.4\%), suffered DM for more than five years $(65.9 \%)$, practiced low-carbohydrate diets $(78 \%)$, and did not have smoking habits $(85.4 \%)$. The demographic characteristics of the patients are presented in Table 1.

Int. J. Public Health Sci. Vol. 8, No. 4, December 2019: 461 - 466 
During the pilot test, the time spent on one interview using the developed questionnaire on the behavior of DM patients was approximately 10-15 minutes, with the average respondents had already understood the content of this questionnaire. This instrument was tested for its validity on 41 patients, and the outcome was 12 valid items or questions with a Pearson correlation coefficient of $>0.308(n=41)$. Meanwhile, the reliability test yielded a Cronbach alpha of 0.78 , meaning that the questionnaire on the behavior of type $2 \mathrm{DM}$ patients can produce reliable, i.e., stable and consistent, results. The validity and reliability test results are presented in Table 2. This result in line with previous study which developed knowladge, attitude, and practice questionnaire called KAP. Independent Cronbach alpha for KAP domains were $0.75,0.75$ and 0.63 , meaning that our result on behavior of $\mathrm{DM}$ patients questionnaire higher than KAP [17].

This study also assessed the construct validity of the questionnaire using Bartlett's test of sphericity to determine the absence or presence of correlation between variables, and the outcome was a significance value of 0.000 . The Kaiser-Meyer-Olkin (KMO) measure of sampling adequacy was 0.546 . With the threshold of suitability $>0.50$, this figure indicates that the instrument suits for factor analysis. In the factor analysis, the 12 questions were reduced or grouped into four domains with an eigenvalue greater than 1. The eigenvalues of Factors 1 to 4 were 3.310, 1.727, 1.458, and 1.243, respectively. The distribution of the questionnaire items in the four domains is as follows. Factor 1 has four questions, namely No. 1, 2, 3, and 4. Meanwhile, questions No. 5, 6, and 7 belong to Factor 2, and only question No. 9 is part of Factor 3. Factor 4 consists of questions No. 8, 10,11, and 12. This result relevant with previous study that developed KAP questionnaire in India. It was found the KMO measure of sampling adequacy was 0.579 [17].

The factor analysis test revealed that Factors 1 and 2 corresponded to two domains designed in the questionnaire, namely the cognitive domain (measured by questions No. 1 through 4 ) and the affective domain (explained in questions No. 5 to 7). Meanwhile, Factors 3 and 4 demonstrated the psychomotor domain of the instrument and showed that questions No. 8, 10, 11, and 12 had similarities in variables, which are medication compliance and lifestyle modification (i.e., physical exercise). As for question No. 9, it was included in Factor 3 because it specifically asked for low-glucose or low-carbohydrate diets.

\begin{tabular}{|c|c|c|}
\hline Demographic Characteristics & $\mathrm{N}$ & $(\%)$ \\
\hline \multicolumn{3}{|l|}{ Sex } \\
\hline Female & 24 & $58.5 \%$ \\
\hline Male & 17 & $41.5 \%$ \\
\hline \multicolumn{3}{|l|}{ Marital Status } \\
\hline Married & 41 & $100 \%$ \\
\hline \multicolumn{3}{|l|}{ Age } \\
\hline$\leq 60$ years old & 17 & $41.5 \%$ \\
\hline$>61$ years old & 24 & $58.5 \%$ \\
\hline \multicolumn{3}{|l|}{ Length of Education } \\
\hline Less than nine years & 9 & $22.0 \%$ \\
\hline $\begin{array}{l}\text { More than nine years } \\
\text { Occupation }\end{array}$ & 32 & $78.0 \%$ \\
\hline Government employee & 5 & $12.2 \%$ \\
\hline Self-employed, labor, in the private sector & 7 & $17.1 \%$ \\
\hline Unemployed (i.e., homemaker, retiree) & 29 & $70.7 \%$ \\
\hline \multicolumn{3}{|l|}{ History of Diabetes Mellitus } \\
\hline Yes & 15 & $36.6 \%$ \\
\hline No & 26 & $63.4 \%$ \\
\hline \multicolumn{3}{|l|}{ Duration of Diabetes Mellitus } \\
\hline$\leq 2$ years & 8 & $19.5 \%$ \\
\hline $3-5$ years & 6 & $14.6 \%$ \\
\hline$>5$ years & 27 & $65.9 \%$ \\
\hline Diet and Eating Pattern & & \\
\hline Low-carbohydrate/sugar diet & 32 & $78.0 \%$ \\
\hline $\begin{array}{c}\text { No low-carbohydrate/sugar diet } \\
\text { Smoking Habit }\end{array}$ & 9 & $22.0 \%$ \\
\hline Yes & 6 & $14.6 \%$ \\
\hline No & 35 & $85.4 \%$ \\
\hline
\end{tabular}

The psychomotor domain was designed to assess three aspects, namely medication compliance, diet or attempts to regulate glucose/carbohydrate intake, and exercise. It describes behaviors formed by lifestyle modification and adherence to medication. It is in line with the instruments developed to measure knowledge, attitude, and practice outcomes in India, Ethiopia, and Malaysia [11, 14, 17-18]. 
The questionnaire was prepared by referring to previous relevant studies. The fundamentals of DM management are self-education and, then, interventions that encourage a lifestyle change, the predefined goal of blood sugar level control, and antidiabetic pharmacological therapy [11]. The cognitive domain was intended to determine how far patients understood DM management, including symptoms and severity of DM, the importance of compliance with pharmacological therapy that administered oral diabetic drugs and insulin. It also aimed to define or set the target of the patient's blood pressure control. Based on previous studies, the majority of DM patients are well-informed of types of antidiabetic drugs and their functions as part of pharmacological treatments but not of the complications or severity of DM and side effects of hypoglycemic risk [15]. Therefore, the understanding of DM patients needs to be examined according to the cognitive domain in the developed questionnaire.

Self-care practice is also required in achieving the target of blood sugar level control [16]. It is strongly dependent on knowledge of the disease and willingness to carry out necessary disease management [16]. In the questionnaire, the affective domain was formulated to measure the patient's awareness of DM and desire to comply with DM therapy. Lifestyle modification can significantly optimize self-care practice as it comprises dietary plan that regulates the consumption of sugar, carbohydrates, fruits, vegetables, and snacks, smoking habit, and physical activities, such as exercise [11, 15]. As for the psychomotor domain, it was designed to measure lifestyle modification among selected DM patients, including physical activity, low-sugar diet, and compliance with medication.

Table 2. The validity test results of the questionnaire on the behavior of DM patients

\begin{tabular}{|c|c|c|}
\hline No & Questionnaire Items by Domain & Pearson correlation coefficients $(\mathrm{N}=41)$ \\
\hline & COGNITIVE & \\
\hline 1 & Do you know that the cause of diabetes is related to the hormone insulin? & $0.596^{* *}$ \\
\hline 2 & $\begin{array}{l}\text { Do you know that oral antidiabetic drugs must be consumed continuously } \\
\text { to control blood glucose or sugar levels? }\end{array}$ & $0.675^{* *}$ \\
\hline 3 & $\begin{array}{l}\text { Do you know that unmanaged diabetes can cause eye damage, kidney } \\
\text { damage, stroke, and coronary heart disease? }\end{array}$ & $0.516^{* *}$ \\
\hline 4 & $\begin{array}{l}\text { Do you know that the signs and symptoms of hypoglycemia (blood sugar } \\
\text { level drops to below } 40 \mathrm{mg} / \mathrm{dl} \text { ) include shakiness, cold sweating, blurred } \\
\text { vision and dizziness, and weakness? } \\
\text { AFFECTIVE }\end{array}$ & $0.413^{* *}$ \\
\hline 5 & $\begin{array}{l}\text { Do you feel that routinely taking antidiabetic medication can control your } \\
\text { blood glucose/sugar levels? }\end{array}$ & $0.553^{* *}$ \\
\hline 6 & $\begin{array}{l}\text { Are you willing to take oral antidiabetic medication regularly to control } \\
\text { your blood glucose/sugar levels? }\end{array}$ & $0.652 * *$ \\
\hline 7 & $\begin{array}{l}\text { Do you assume that continuous administration of oral antidiabetic } \\
\text { medication can cause kidney failure? } \\
\text { PSYCHOMOTOR }\end{array}$ & $0.377 *$ \\
\hline 8 & $\begin{array}{l}\text { Do you frequently carry oral antidiabetic medication when traveling (out } \\
\text { of town) or working? }\end{array}$ & $0.434 * *$ \\
\hline 9 & $\begin{array}{l}\text { Have you reduced your sugar/carbohydrate intake to control your blood } \\
\text { glucose/sugar levels? }\end{array}$ & $0.314 *$ \\
\hline 10 & Do you exercise (walking or DM gymnastics) at least 3-4 times a week? & $0.450 * *$ \\
\hline 11 & $\begin{array}{l}\text { Do you still take oral antidiabetic medication even though the clinical } \\
\text { symptoms or signs of diabetes mellitus are no longer apparent? }\end{array}$ & $0.626^{* *}$ \\
\hline 12 & Did you forget to take medicine last week? & $0.514 * *$ \\
\hline
\end{tabular}

The transtheoretical model developed by DiClemente, differentiates four levels of behavior: pre-contemplation, contemplation, preparation, and action [19]. Based on the behavior level, the type 2 DM patients observed in this study were distributed into $61 \%$ pre-contemplation, $26.8 \%$ contemplation, $7.3 \%$ preparation, and $4.9 \%$ action. Most patients were at the level of pre-contemplation (61\%), which means that patients have not acquired a cognitive understanding of DM management and are not willing to take medication regularly. At this stage, the required interventions include any attempts to improve education on DM management and motivations to increase compliance with therapy. Around one-fourth of the patients $(26.8 \%)$ were at the level of contemplation, indicating that patients are aware of the disease and have the desire to change or improve their behavior from contemplation to preparation and action/maintenance. Meanwhile, only a small proportion of them was at the stage of preparation $(7.3 \%)$ and action $(4.9 \%)$. These findings show that some patients have started to improve their compliance with medication, dietary plans, low-carbohydrate intake, and exercise. 
Table 3. The distribution of type 2 DM patients by level of behavior

\begin{tabular}{cc}
\hline Levels of Behavior & $\mathrm{N}(\%)$ \\
\hline Pre-contemplation & $25(61.0)$ \\
Contemplation & $1(26.8)$ \\
Preparation & $3(7.3)$ \\
Action & $2(4.9)$ \\
\hline
\end{tabular}

\section{CONCLUSION}

This research showed that the questionnaire on attitude of type $2 \mathrm{DM}$ patients is valid and reliable to be used in primary health care service. This questionnaire can be used by the pharmacist to obtain the data on pre-screening regarding the level of attitude of type $2 \mathrm{DM}$ patients in primary health care service to improve the compliant and the education of the patient regarding the treatment.

\section{ACKNOWLEDGEMENTS}

Firstly we would like to thank for KEMENRISTEK DIKTI as a founder in this study. The second we would like to thank the Pharmacy Faculty of Universitas Ahmad Dahlan for granting us the permission of this study. We are also grateful to PKU Muhammadiyah Yogyakarta Hospital for granting us the permission of this study. Our thanks to all pharmacists Nurma, S.Farm.,Apt, Neni S.Farm., Apt. who have helped technically in this study. Our thanks to all of Diabetes Mellitus patients for voluntarily participating, thank you for your time. Also thanks to Amarily Suta for revision of grammer in this script writing.

\section{REFERENCES}

[1] Shareef J, Fernandes J, and Samaga L. Assesment of Clinical Pharmacist Interventions in Drug Therapy in Patients with Diabetes Mellitus in a Tertiary Care Teaching Hospital, Diabetes \& Metabolic Syndrome: Clinical Research and Reviews. vol.10, no.2:pp 82-87, 2013.

[2] Asche, C, Joane L, and Christopher C. A Review of Diabetes Treatment Adherence and The Association with Clinical and Economic Outcomes, Clin Ther. vol.33: no.1, pp:74-109. 2011.

[3] RI Ministry of Health, Number of Patients with Diabetes in the 4th Rank in the World, Ministry of Health Republic of Indonesia, Jakarta, 2013.

[4] Cramer, J.A, Benedict A, Muszbek N, Keskinaslan A, and Khan ZM. The Significance of Compliance and Persistence in the Treatment of Diabetes, Hypertension and Dyslipidaemia: a Review, International Journal of Clinical Practice, vol.62, no.1, pp. 76-87, 2008.

[5] Ministry of Health, Guidelines for Counseling Pharmaceutical Services in Health Facilities, Directorate General of Pharmaceutical and Medical Devices Development, Ministry of Health Republic of Indonesia, Jakarta, 2006.

[6] Perez, L.E.G, Alvarez M, Dilla T, Gil-Guillen V, and Orozco-Beltran D. Adherence to Therapies in Patients with Type 2 Diabetes, Springer Heathcare, vol.4, no.2, pp.175-194, 2013.

[7] Saleh F, Mumu SJ, Ara F, Hafez MA, and Ali L. Non-Adherence to Self-Care Practices \& Medication and Health Related Quality of Life among Patients with Type 2 Diabetes: a Cross-Sectional Study, Bio Med Central Public Health, vol.14, no.1, pp.1-8, 2014.

[8] Aldossari Khaled, Mohamed A, Sanna K, Jaman A, Sameer A, Ibrahim A, et al. Assessment of Levels of knowledge, attitude and practice about diabetes mellitus (DM), its complications and self-management of diabetic patients in AlKharj city, Saudi Arabia. International Journal of Advanced Research, Vol 3, Issue 5, 23-32, 2015.

[9] CMR Guidelines for Management of Type 2 Diabetes. Non-Pharmacological Management of Diabetes, ICMR GUIDE LINES, 2005

[10] Kisokanth, G., Prathapan, S., Indrakumar, J., Joseph, J., Factors Influencing Self-Management of Diabetes Mellitus: a review article, Journal Diabet, vol.3, no.1, 2013.

[11] Mustefa AA, Esayas T, Belayneh K, Mustefa A, Muluneh F, and Thirumurugan G. Assessment of Knowledge, Attitude and Practices Regarding Life Style Modification among Type 2diabetic Mellitus Patients Attending Adama Hospital Medical College, Oromia Region, Ethiopia. Global Journal of Medical Research. Vol 14, Issue 7, 2014.

[12] Saputri ZG, Haafizah D, Imaniar NF, and Faiza A. The Validation of Patient Knowledge Questionnaire for Patients with Diabetes Mellitus and Hyperlipidemia, Pharmaciana, vol.8, no.2, 2018.

[13] Saputri ZG, Akrom, Dini SM. Validation of Behaviour Measurement Instrument of Patients with Diabetes Mellitus and Hypertension, IOP Conf. Series, Materials Science and Engineering 259, 2017.

[14] Chinappan S, Sivanandy P, Sagaran R, Molugulu N. Assesment of Knowladge of Diabetes Mellitus in the Urban Areas of Klang District, Malaysia, MDPI Pharmacy, vol.5, no. 11, pp. 1-8, 2016.

[15] Pin Chow Ee, Mohamed Azmi H, Fahad S, et al. Effects of pharmacist-led patient education on diabetes-related knowledge and medication adherence: A home-based study. Health Education Journal, page 1-13. 2015.

[16] Malathy R, Narmadha MP, Ramesh S, et al. Effect of a Diabetes Counseling Programme on Knowledge, Attitude and Practice among Diabetic Patients in Erode District of South India. Journal of young pharmacist, Vol 3. No 1, 2011. 
[17] Reethesh, SR, Piyush R, Charu A, et al. Development and validation of questionnaire assessing knowledge, attitude, and practices about obesity among obese individuals. Indian journal of endocrinology and metabolism. 23(1), 102, 2019.

[18] Palaian S, Mukhyaprana P, Ravi S. Patient Counseling by Pharmacist Focus on Chronic Illness, Pak. J. Pharm. Sci, vol.19, no.1, pp.62-65, 2006.

[19] DiClemente C., Delahanty, J., Jean, F., Earley, M., Garay,M., Preston,G., Meredith, H., Angela, P., Kristina, S., Onna, V., Katherine, W., 1994, Health and Addictive Behaviours Investigating Transtheoritical Solution, (Online) Transtheoritical Model of Behaviour Change Measure, (http://www.umbc.edu/psyc/habits/content/ttm_measure_/index.html, diakses pada 18 Mei 2014). 